\title{
Transboundary movements of waste
}

\author{
Sophie Bernard *
}

August 24, 2010

\footnotetext{
*University of Ottawa, 55 Laurier E, Ottawa ON Canada, K1N 6N5 (sbern052@uottawa.ca). Research supported by the FQRSC (Fonds québécois de recherche sur la société et la culture). Special thanks to Louis Hotte and seminar participants at McGill University.
} 


\begin{abstract}
In a stylized model of international trade, a monopolist in the North exports secondhand products to a representative firm in the South to be reused as intermediate goods, with potential trade gains. The degree of reusability of waste products is a crucial choice variable in the North. This is because with a lack of international vigilance, nonreusable waste can be mixed illegally with the reusable waste. I explore the driving forces for the movement of illegal waste, paying particular attention to the role of local waste regulations, such as the EU's Waste Electrical and Electronic Equipment directive. Under mild conditions, it is shown that increased regulation stringency in the North leads its firm to reduce the degree of reusability of its products. As a result, the flow of non-reusable waste to the South increases, providing another channel for the Pollution Haven Hypothesis.
\end{abstract}

Keywords: second-hand products, environmental regulation, trade.

JEL classification: F18, L10, O20, Q53 


\section{Introduction}

The phenomenon of transboundary shipment of waste is driven by the scarcity of traditional landfill capacity in industrialized countries, where post-consumption waste has become a major concern. Governments have recently introduced new types of regulations, called extended producer responsibility, which make firms and producers responsible for waste disposal costs. The European Union's Directive on Waste Electrical and Electronic Equipment (WEEE) introduced in 2005 is an example. When firms internalize the cost of eco-friendly waste disposal, they tend to reduce the use of hazardous material and improve the reusability of their products. Also, some regulations directly aim at improving the quality of waste, like the European Union's End of Life Vehicle Directive introduced in 2006, which stipulates that every new vehicle must have recyclable content of 85 percent (95 percent by 2015). The current paper analyzes the impact of such regulations ${ }^{1}$ when trade of used products is allowed for.

Although there are second-hand good markets in developed countries, the demand for such goods is often low due to technological obsolescence or regulations (like the technical inspections in many European countries that ensure that vehicles in poor conditions must be taken off the road). However, due to the gap in wealth between industrialized and industrializing economies, developing countries have a positive demand for some products that would be defined as waste in the North. This is the case of many e-waste, used vehicles ${ }^{2}$ and recycled materials [Janischweski et al. 2003, Beukering and Bouman 2001]. In addition, industrial processes which reuse waste are typically qualified as labor-intensive. Therefore, there is a natural movement of waste from developed to less developed countries.

Two important sets of regulations govern transboundary movements of waste. The Basel Convention and EU regulations both restrict the shipment of waste and their disposal. So as

\footnotetext{
${ }^{1}$ For more details on the different instruments see Toffel et al. (2008).

${ }^{2}$ Janischweski et al. (2003) show that countries in East and West Africa import more second-hand vehicles than new ones. These cars have a particularly poor quality and are often more than 15 years old.
} 
to minimize the environmental impact of waste management, the export of hazardous waste, e-waste and used vehicles from OECD to non-OECD countries is prohibited. However, the difference in the treatment and disposal costs remains one of the driving forces for transboundary shipments. Non-OECD countries often have low-cost, albeit environmentally inadequate, facilities. Czarnomski and Webb (2006) give the example of a PC monitor that costs around $£ 5$ to be recycled in the UK versus traders willing to pay up to $£ 3$ for a "visibly undamaged" monitor. The export of such e-waste to non-OECD countries often ends up incinerated in open fires, a practice which is unsafe both for the environment and human health [EEA 2009].

When combining i) the difference in local waste regulations, ii) the labor intensity of waste reuse industries and iii) the demand-driving forces, developing countries possess all the necessary characteristics to be pollution havens. Because of environmental concerns in the North, stricter environmental regulations are implemented and increase production costs of dirty industries (waste management) at home. The Pollution Haven Hypothesis stipulates that dirty industries will migrate from developed to less developed countries.

In order to minimize the cost of complying with extended producer responsibility programs, firms may consider legal and illegal ${ }^{3}$ shipments of waste. The New York Times reporter Elisabeth Rosenthal (September 27, 2009) has investigated this market. She reports that, according to expert's estimation, around 16 percent of the exports are illegal. She also underlines that fewer restrictions on waste exports in the United States and Canada produce a large flow of waste legally exported to developing countries. Other sources say that illegal shipments reported by non-OECD countries are in average 22000 tonnes per year, which represents 0.2 percent of notified waste [EEA 2009]. These illegal activities take different forms: transporting waste on the black market, mixing different types of waste or declaring hazardous waste as non-hazardous. This research concentrates on yet another type

\footnotetext{
${ }^{3}$ The United States have fewer restrictions on waste exports than Europe because they did not ratify the Basel convention. As a result, waste shipments are generally legal.
} 
of illegal practice: classifying waste as second-hand goods. When products are classified as second-hand goods, they are no longer governed by international waste regulations and can be traded with developing countries.

There are two used good market characteristics that I refer to as the lack of international vigilance. The first one is that second-hand goods appear to be a one-size-fits-all category for recyclable, remanufacturable and second-hand products. As a result of these institutional ambiguities, international waste regulations are subject to different interpretations. Hence, authorities and enforcement agencies of the countries misclassify waste as used goods [Fischer et al. 2008]. Such misclassifications have been observed for e-waste and used vehicles ${ }^{4}$ [Czarnomski et al. 2006 and Janischweski et al. 2003], and also for used clothes, car tires and other types of waste [Fischer et al. 2008]. Authorities from developing countries can also turn a blind eye to this illegal market. Reluctant to improve monitoring, they prefer to protect the imported waste business and the labor market it generates [Yardley, April 23, 2010].

The second characteristic qualified as the lack of international vigilance is that many used products are traded along with new ones. This situation makes it hard to keep track of them. One way to evaluate the scale of these markets is to compare prices. For instance, the average price of all exported television sets from Europe is $339 €$ whereas the price drops to $28 €$ when exported to Nigeria, Ghana or Egypt (where more than 1000 used television sets arrive every day) [EEA 2009]. For both waste and used goods, the lack of precision in this identification renders market analysis difficult [EEA 2009].

The United-States and India, along with other countries, have led discussions during the Doha round. They want the WTO to undertake initiatives in order to regulate the movement of used products. Today, the WTO has only a draft version of proposed legislation, in which

\footnotetext{
${ }^{4}$ Czarnomski et al. (2006) observes that a significant amount of what is considered WEEE in OECD countries is exported illegaly to West Africa as second hand goods. Also, Janischweski et al. (2003) note that transactions where vehicles exported in "top condition" happen to be "cars without an engine" are so common that they name it the Lemon Rule.
} 
it is recommended that the import of used products be banned. As a result, developed countries see the market for their used products reduced. ${ }^{5}$ Under proper regulations, there is potential for gains from liberalizing trade in used goods as shown in Clerides (2008).

One rationale behind extended producer responsibility programs is that, by internalizing the cost of waste disposal, firms choose a higher level of reusability. The current paper observes the effect of higher disposal costs in the presence of an international second-hand goods market. In a stylized North-South model, a representative firm in the South can purchase second-hand products from the firm in the North as intermediate goods. Because of a lack of international vigilance, illegal shipments of non-reusable waste are mixed with the exported goods. The model explores the driving forces of illegal waste movements with particular attention to differences in local disposal costs. It also observes the impact of higher international vigilance. Results show that a large difference in waste treatment costs can induce firms in the North to reduce the reusability of their products. An increase in international vigilance can also bring counterintuitive results.

Few authors have studied extended producer responsibility programs. Runkel (2003) studies the influence of four instruments on product durability and welfare. He also explores different competitive environments and shows that the application of an extended producer responsibility program under imperfect competition can lead to a welfare reduction. Fleckinger and Glachant (2010) are concerned with the fact that such programs are precisely designed in order for producers to meet their obligations in their own way. They study a duopoly of producers and compare scenarios where producers manage their waste on their own and where they cooperate through a recycling center (called producer responsibility organization). They conclude that such a cooperation could lead to suboptimal outcomes and justifies government intervention.

\footnotetext{
${ }^{5}$ While some countries forbid the import of used goods, others apply prohibitive tariffs. Uganda qualifies used goods as sensitive and applies a tariff of $55 \%$, beyond the common external tariff of $25 \%$. (See www.allafrica.com, 12 February 2009)
} 
The theoretical literature on trade in used products is still very scarce. Bond (1983) develops a model based on differences in factor prices and technologies in order to explain trade in equipment between firms. He also tests it empirically. The empirical literature on the topic is more common with Frazer (2008) who explains the decline in apparel production in Africa through used-clothing donations, ${ }^{6}$ or Clerides (2008) who describes the gains from trade in used vehicles. To the best of my knowledge, the current paper is the first research project which integrates movements of illegal and reusable waste into an economic model.

Section 2 introduces the model and section 3 solves for the equilibrium. Section 4 presents effects of a change in the disposal cost in the North as well as the consequences of stricter enforcement in international vigilance. Section 5 concludes.

\section{The Model}

The problem is set in a basic model of international trade where a representative firm in a developing country (the South) imports inputs (used products) from the firm in the developed country (the North).

New final goods are produced in quantity $x_{N}$ by a monopolist in the North and they are consumed at home. At the end of the products' lifetime, the firm is subject to an extended producer responsibility program. In order to comply with the regulation, the firm creates a recycling center ${ }^{7}$ recognized by the government, which manages the collection and the

\footnotetext{
${ }^{6}$ Similar to food aid, used-clothing imports harm local producers. The problem of used good imports as an obstacle for economic development is also largely discussed in Janischweski et al. (2003).

${ }^{7}$ For instance, in France, four recycling centers are recognized today by the government in order to comply with the WEEE directive. Eco-systèmes gathers many stockholders like LG, Moulinex, Philips and Samsung (see www.eco-systemes.com) while the European Recycling Platform was founded by Braun, Electrolux, HP and Sony (see www.erp-recycling.org). The two others are Ecologic (see www.ecologic-france.com) and Recylum (www.recylum.com). The last one treats only used lamps.

In the curent model, the assumption of a monopolist in the North recalls the assumption of Fleckinger and Glachant. They argue that recycling centers bring a risk of collusion and they explore this issue. Producers collude perfectly and choose the quality (related to the $q$ here) that would be selected in the monopolistic case.
} 
disposal of e-waste. The firm is both client and owner of the recycling center. For simplicity, the recycling center's activities will be merged in the firm's objective function.

A portion of the used products are classified as reusable and can be exported to the South as an input to their production. The North exports $w_{e}$ used goods at price $p_{e}^{w}$. The subscript $e$ refers to the export values. The rest must be disposed in an eco-friendly manner, at constant unit cost of disposal $d_{N}$. The firm can also increase the fraction of reusable products $q$ at an increasing and convex unit $\operatorname{cost} c_{N}(q)$.

The firm faces decreasing inverse demand for its new products:

$$
p_{N}=\beta-x_{N},
$$

where $\beta$ represents the North's market size.

The firm in the South is a representative firm of a market in perfect competition. It employs used products as an input where $x_{S}$ final goods are sold at exogenous price $p_{S}$. The firm can either apply some transformation processes like cleaning, remanufacturing or repairing; or it can act as an intermediary in shipping, handling and reselling. One used good is necessary for the production of one output. Production costs are divided in three parts. First, they have to acquire used products from the North. They buy a basket (or a container) of these used products that are previously classified as reusable. They pay $p_{m}^{w}$ for each of the $w_{m}$ imported good. The subscript $m$ refers to the import values.

$q$ denotes the proportion of goods $x_{N}$ that are reusable at the end of their lives. The proportion $1-q$ is non-reusable and, under international regulations, should not be exported to the South. However, the lack of international vigilance causes a fraction $\sigma \in(0,1)$ of these non-reusable goods to be misclassified. The actual fraction of used goods classified as

Since trade with the South passes through the recycling center, the assumption captures also the North's market power vis-à-vis the firm in the South. 
reusable is:

$$
\stackrel{\circ}{q}=q+(1-q) \sigma
$$

As a result, in the basket of imported goods, only a fraction $\bar{q}=q / /^{\circ}$ can be used as inputs. $\bar{q}$ is referred to as the purity of the basket. ${ }^{8}$

The second part of production costs reflects the sorting and the transformation processes, which decreases with $\bar{q}$. The representative firm has perfect information about the purity of baskets. Once sorted as reusable, goods require different degrees of intervention - from simple cleaning to change in parts - and the marginal cost increases with $x_{S}$. These transformation costs take the form: $c_{S}\left(x_{s} ; \bar{q}\right)=x_{s}^{2} / 2 \bar{q}$.

The South can also adopt an extended producer responsibility program $d_{S}$ which constitutes the third part of total costs. It is assumed that the South has laxer environmental regulations so that their waste disposal cost is lower than in the North: $d_{S} \leq d_{N}$.

\subsection{The market structure}

The market structure is described by the following two stage game. Local disposal costs, $d_{S}$ and $d_{N}$, and the state of international (lack of) vigilance, $\sigma$, are given. In the first stage, the monopolist firm in the North produces new goods in quantity $x_{N}$ and selects the level of reusability $q$. The firm also selects the level of exports, $w_{e}$.

The representative firm in the South is a price taker on the international market. In the second stage, the level of imports as well as the quantity of output, $w_{m}$ and $x_{S}$, are determined in the South.

Since the firm in the North is the leader, its decision when selecting the level of exports

\footnotetext{
${ }^{8}$ It is assumed that the monopolist does not sort waste in order to improve purity. Sorting is a labor intensive activity and is hence too costly for the firm in the North. As a result, purity depends only on the level of reusability $q$.
} 
incorporates the representative firm's reaction function.

\section{The equilibrium}

The profit functions for the firm in the North and in the South are respectively:

$$
\begin{aligned}
\pi_{N}= & p_{N} x_{N}-c_{N}(q) x_{N}+p_{e}^{w} w_{e}-\left(x_{N}-w_{e}\right) d_{N} \\
& \text { where } p_{N}=\beta-x_{N} \\
& \text { and } w_{e} \leq \stackrel{\circ}{q} x_{N} \\
\pi_{S}= & p_{S} x_{S}-c_{S}\left(x_{S} ; \bar{q}\right)-\left(p_{m}^{w}+d_{S}\right) w_{m} \\
& \text { where } c_{S}\left(x_{s} ; \bar{q}\right)=x_{s}^{2} / 2 \bar{q} \\
& \text { and } x_{S} \leq \bar{q} w_{m}
\end{aligned}
$$

Equation 1 means that the monopolist cannot export more than the proportion of used goods classified as reusable. It is assumed that the international market is small enough so that equation 1 is not binding in equilibrium. The scenario of a corner solution, when the South imports all goods classified as reusable is not considered here. ${ }^{9}$ Equation (2) says that the firm's output in the South is limited by the amount of reusable inputs $\bar{q} w_{m}$.

Using backward induction, the final stage is solved first. The representative firm's problem is:

$$
\begin{aligned}
& \max _{w_{m}} \pi_{S}=p_{S} \bar{q} w_{m}-\left(\bar{q} w_{m}\right)^{2} / 2 \bar{q}-\left(p_{m}^{w}+d_{S}\right) w_{m} \\
& \text { s.t. } x_{S} \leq \bar{q} w_{m} .
\end{aligned}
$$

\footnotetext{
${ }^{9}$ It implies that $\beta$ is large enough. Formally, $\beta>\left(p_{s} \bar{q}+d_{N}-d_{S}\right) \frac{2+2 \bar{q}^{\circ}{ }^{2}}{q}+c_{N}(q)+d_{N}$.
} 
In equilibrium, the constraint is binding

$$
x_{S}=\bar{q} w_{m}
$$

and the first order condition leads to the following reaction demand function for imported goods:

$$
p_{m}^{w}=p_{S} \bar{q}-w_{m} \bar{q}-d_{S}
$$

In equilibrium, the international market clears:

$$
\begin{aligned}
& w_{m}=w_{e}=w \text { and } \\
& p_{m}^{w}=p_{e}^{w}=p^{w} .
\end{aligned}
$$

The first stage in the game is the firms's problem in the North. Using equations (4) to (6), the monopolist's problem becomes:

$$
\max _{w, x_{N}, q} \pi_{N}=\left(\beta-x_{N}\right) x_{N}-c_{N}(q) x_{N}+\left(p_{S} \bar{q}-w \bar{q}-d_{S}\right) w-d_{N}\left(x_{N}-w\right) .
$$

The first order conditions lead to:

$$
\begin{aligned}
w & =\frac{p_{S} \bar{q}+d_{N}-d_{S}}{2 \bar{q}} \\
x_{N} & =\frac{\beta-c_{N}(q)-d_{N}}{2} \\
\frac{\partial \pi_{N}}{\partial q} & =\left(\beta-c_{N}(q)-d_{N}\right) \frac{-c_{N}^{\prime}(q)}{2}+\frac{\partial \bar{q}}{\partial q}\left(\frac{\left(p_{S} \bar{q}\right)^{2}-\left(d_{N}-d_{S}\right)^{2}}{4 \bar{q}}\right)=0
\end{aligned}
$$

Where equation (7) is the level of exports, (8) is the production of new goods and (9) is the optimality condition for the choice of reusability $q$. It is assumed that the second order 
condition for a maximum is satisfied. ${ }^{10}$ Using equations (4) to (8), the price of exports becomes:

$$
p^{w}=\frac{p_{S} \bar{q}-d_{N}-d_{S}}{2}
$$

The equilibrium in this industry is characterized by equations (3) to (10). For the purpose of the analysis, illegal shipments, which is the non-reusable share of exports, take the form:

$$
(1-\bar{q}) w
$$

\section{Disposal cost and international vigilance}

\subsection{Disposal cost and the Pollution Haven Hypothesis}

One of the rationales behind extended producer responsibility is that, by internalizing the cost of waste disposal, firms choose a higher level of reusability. Let us see what happens, in the presence of a secondary market in developing countries, when the North applies higher disposal costs.

We have:

$$
\begin{aligned}
\operatorname{sign} \frac{\partial q}{\partial d_{N}} & =\operatorname{sign} \frac{\partial^{2} \pi_{N}}{\partial q \partial d_{N}} \text { where } \\
\frac{\partial^{2} \pi_{N}}{\partial q \partial d_{N}} & =\frac{c_{N}^{\prime}(q)}{2}+\frac{\partial \bar{q}}{\partial q}\left(\frac{-2\left(d_{N}-d_{S}\right)}{4 \bar{q}}\right)
\end{aligned}
$$

Proposition 1 For all $q$, there exists a unique $\phi>0$ such that

$$
\begin{gathered}
\frac{\partial q}{\partial d_{N}} \gtreqless 0 \Longleftrightarrow d_{N}-d_{S} \lesseqgtr \phi \\
10 \frac{\partial^{2} \pi_{N}}{\partial q^{2}}=\frac{c_{N}^{\prime}(q)^{2}}{4}-\left(\beta-c_{N}(q)-d_{N}\right) \frac{c_{N}^{\prime \prime}(q)}{2}+\frac{\partial^{2} \bar{q}}{\partial q^{2}}\left(\frac{\left(p_{S} \bar{q}\right)^{2}-\left(d_{N}-d_{S}\right)^{2}}{4 \bar{q}}\right)+\frac{\partial \bar{q}}{\partial q}\left(\frac{\left(p_{S} \bar{q}\right)^{2}+\left(d_{N}-d_{S}\right)^{2}}{4 \bar{q}}\right)
\end{gathered}
$$


in particular, for $d_{N}-d_{S}=0, \partial q / \partial d_{N}>0$. Note that $\phi$ depends on the initial value of $q$, determined by the equilibrium prior to the change in policy.

Proof. We know that $c_{N}^{\prime}(q)$ and $\partial \bar{q} / \partial q$ are positive. Therefore, equation (11) strictly decreases when $d_{N}-d_{S}$ increases. Since $\partial q / \partial d_{N}>0$ when $d_{N}-d_{S}=0$, then $\partial q / \partial d_{N}=0$ when $d_{N}-d_{S}=\phi>0$.

One can see that when the South regulates as much as the North, i.e. $d_{N}=d_{S}$, the level of reusability $q$ increases unambiguously with the strength of local waste regulation $d_{N}$. However, when the difference in disposal costs is large enough, more stringent waste regulation in the North reduces the choice of reusability and induces an increased amount of illegal shipments. These observations are explicitly formulated in the following proposition.

Proposition 2 In equilibrium, the effect of an increased disposal cost in the North $d_{N}$ depends on the difference between local disposal costs, $d_{N}-d_{S}$ :

- When the extended producer responsibility is similar between the two countries, i.e. when $d_{N}-d_{S}<\phi$, the firm in the North, which internalizes the South's disposal cost, does not benefit from a large difference between local and foreign disposal costs. Therefore, the firm will increase the level of reusability of its products $q$ and propose baskets with higher purity $\bar{q}$. Because exports are potentially higher, the total effects on the amount of illegal shipments, $(1-\bar{q}) w$, as well as on the price of exports $p^{w}$, are ambiguous.

- When the extended producer responsibility is largely different between the two countries, i.e. when $d_{N}-d_{S}>\phi$, the firm in the North benefits from a large difference between its local disposal cost and the internalized South's cost. The monopolists' strategy will therefore aim at exporting non-reusable goods, cheaper to be disposed of in the South. The firm in the North will reduce the reusability of its products $q$ and reduce the purity of exported baskets $\bar{q}$. This strategy lowers the price of exports $p^{w}$ and causes an increased 
demand of used goods. With a higher level of exports and lower purity, illegal shipments $(1-\bar{q}) w$ increase unambiguously. If purity were to stay high, the demand in the South would get saturated quickly and the level of exports would remain too low relative to the increasing disposal cost in the North and the possibility to "dump" non-reusable waste in the South.

In the light of Proposition 2, the initial intention of an extended producer responsibility program is respected when the difference in local regulations shows little difference. As the disposal cost increases in the North, the monopolist is more likely to consider illegal shipments instead of improving the level of reusability. This result is in line with the pollution haven hypothesis since the difference in environmental regulation between developed and less-developed countries brings a flow of pollution (waste) towards poor countries.

\subsection{International vigilance}

This section presents what occurs when international vigilance increases. We have:

$$
\begin{aligned}
& \operatorname{sign} \frac{\partial q}{\partial \sigma}=\operatorname{sign} \frac{\partial^{2} \pi_{N}}{\partial q \partial \sigma} \text { where } \\
& \frac{\partial^{2} \pi_{N}}{\partial q \partial \sigma}=\frac{\partial^{2} \bar{q}}{\partial q \partial \sigma}\left(\frac{\left(p_{S} \bar{q}\right)^{2}-\left(d_{N}-d_{S}\right)^{2}}{4 \bar{q}}\right)+\frac{\partial \bar{q}}{\partial q} \frac{\partial \bar{q}}{\partial \sigma}\left(\frac{\left(p_{S} \bar{q}\right)^{2}+\left(d_{N}-d_{S}\right)^{2}}{4 \bar{q}}\right) .
\end{aligned}
$$

The second term in equation (12) is always negative. It represents the variation in the marginal revenue of exports due to a variation in the terms of trade. All else equal, as vigilance increases ( $\sigma$ decreases), purity increases as well as the marginal revenue of each exported unit. The first term represents the variation in the marginal revenue of exports due to a variation in the marginal effect of the level of reusability $q$. Looking at the optimality condition for the choice of $q$ (equation 9), we know that $\left(p_{S} \bar{q}\right)^{2}-\left(d_{N}-d_{S}\right)^{2}$ is positive in equilibrium. 
Proposition 3 There exists $\rho>0.5$ such that

$$
\frac{\partial q}{\partial \sigma} \gtreqless 0 \Longleftrightarrow \bar{q} \gtreqless \rho
$$

The effect of an increase in international vigilance (a reduction in $\sigma$ ) on reusability $q$ depends on the initial value of purity $\bar{q}$, prior to the change in policy:

- When the initial purity is small, i.e. when $\bar{q}<\rho$, an increase in international vigilance unambiguously leads to an improvement in the level of reusability.

- When the initial purity is large, i.e. $\bar{q}>\rho$, an increase in international vigilance leads to a reduction in the level of reusability.

Proof. Looking at equation (12), we see that $\frac{\partial q}{\partial \sigma}>0 \Leftrightarrow \frac{\partial^{2} \bar{q}}{\partial q \partial \sigma}\left(-\frac{\partial \bar{q}}{\partial q} \frac{\partial \bar{q}}{\partial \sigma}\right)^{-1}>\frac{\left(p_{S} \bar{q}\right)^{2}+\left(d_{N}-d_{S}\right)^{2}}{\left(p_{S} \bar{q}\right)^{2}-\left(d_{N}-d_{S}\right)^{2}}$. For the specific form of $\bar{q}$, the left hand side increases asymptotically with the initial value of $\bar{q} \in(0,1)$ (for a given $\bar{q}(q, \sigma)$, obtained by any combination of $q$ and $\sigma$, the left hand side is constant) and is positive if only if $\bar{q}>0.5$ since

$$
\partial^{2} \bar{q} / \partial q \partial \sigma \lesseqgtr 0 \Leftrightarrow \bar{q} \lesseqgtr 0.5
$$

The right hand side is positive and decreasing in $\bar{q}$. Therefore, $\rho$ exists and occurs at $\rho>0.5$.

When purity is large, equation (13) becomes positive, which means that, with an increase in international vigilance, an increase in the level of reusability has a smaller effect on purity. When purity is large enough, this incites the firm in the North to reduce the level of reusability.

Most variables of interest in this model depend on purity $\bar{q}$, which varies not only with the level of reusability $q$, but also with international vigilance $\sigma$. A change in international vigilance affects purity directly through $\partial \bar{q} / \partial \sigma$ and indirectly through $(\partial \bar{q} / \partial q) *(\partial q / \partial \sigma)$. 
When an increase in international vigilance leads to a reduction in reusability, the two effects work in opposite directions.

Proposition 4 The total effect of an increase in international vigilance (a reduction in $\sigma$ ) on purity $\bar{q}$ is positive if only if

$$
\frac{d \bar{q}}{d \sigma}=\frac{\partial \bar{q}}{\partial q} \frac{\partial q}{\partial \sigma}+\frac{\partial \bar{q}}{\partial \sigma} \leq 0 \Longleftrightarrow \frac{\partial q}{\partial \sigma} \leq \frac{q(1-q)}{\sigma}
$$

The effects on trade and illegal shipments vary according to the following rule:

- If $\frac{\partial q}{\partial \sigma}<\frac{q(1-q)}{\sigma}$, purity increases with international vigilance. In this case, the quantity of exports $w$ decreases as well as illegal shipments, $(1-\bar{q}) w$.

- If $\frac{\partial q}{\partial \sigma}>\frac{q(1-q)}{\sigma}$, purity decreases as international vigilance increases. In this case, the quantity of exports $w$ increases as well as illegal shipments, $(1-\bar{q}) w$.

From Propositions 3 and 4, if purity is initially small, then it increases with international vigilance, i.e. $\bar{q}<\rho \Leftrightarrow \partial q / \partial \sigma<0<q(1-q) / \sigma$. If international vigilance keeps increasing, purity raises and eventualy becomes large when $\bar{q}>\rho$.

In some contexts, an improvement in international vigilance will have the opposite effect than what was intended from such a regulation. From Proposition 3, we know that this scenario occurs only when purity is initially high, i.e. $\partial q / \partial \sigma>q(1-q) / \sigma>0 \Longrightarrow \bar{q}>\rho$. All else equal, improving international vigilance increases purity. The monopolist who wants to keep a lower level of purity will therefore reduce its level of reusability. When purity is already high, the benefit of reducing purity through $q$ can be larger than the benefit, through the terms of trade, of keeping it high. In this case, more international vigilance intensifies illegal shipments. 


\section{Conclusion}

This paper considers a North-South model where used durable goods in the North are imported by the firm in the South as an input to production. The lack of international vigilance allows for illegal waste to be mixed with reusable products.

In order to look at the Pollution Haven Hypothesis, special attention is given to large differences in local waste regulation between the two countries. It appears that the current application of extended producer responsibility programs, which makes producers responsible for the cost of waste disposal, opens up the valve to illegal shipments of waste. Conversely, trade with countries applying similar regulations would conserve the initial intention of such programs: more stringent regulations in the North leads to a higher level of reusability.

International vigilance also plays an important role. Better enforcement of international agreements leads to a reduction in illegal shipments of waste and an increase in the level of reusability. However, when the level of reusability is already high, better enforcement makes higher reusability less attractive. In some cases, lowering the level of reusability provides more benefit than the improvement in the term of trade. The producer using a high level of reusability would therefore present adverse behavior in case of improved international vigilance.

These results partially come from the fact that producers can manage their obligations in their own way. Because the recycling centers are owned by the producers, they have the incentive to export waste illegally in order to reduce the overall cost of waste disposal.

\section{References}

Beukering, Pieter J.H. Van, and Mathijs N. Bouman (2001) 'Empirical evidence on recycling and trade of paper and lead in developed and developing countries.' World Development $29,1717-1737$

Bond, Eric W. (1983) 'Trade in used equipment with heterogeneous firms.' The Journal of Political Economy 91, 688-705 
Clerides, Sofronis (2008) 'Gains from trade in used goods: Evidence from automobiles.' Journal of International Economics 76, 322-336

Czarnomski, Sarah, and Barry Webb (2006) 'IMPEL-TFS threat assessment project: The illegal shipment of waste among impel member states.' Technical Report, Environment Agency England and Wales, Jill Dando Institute of Crime Science, University College London.

EEA (2009) 'Waste without borders in the EU? Transboundary shipments of waste.' Technical Report, European Environment Agency

Fischer, Christian, Nanja Hedal, Rikke Carlsen, Karin Doujak, David Legg, Judith Oliva, Sara Lüdeking Sparvath, Matti Viisimaa, Thomas Weissenbach, and Mads Werge (2008) 'Transboundary shipments of waste in the EU. developments 1995-2005 and possible drivers.' Technical Report, European Topic Centre on Resource and Waste Management, European Environment Agency

Fleckinger, Pierre, and Matthieu Glachant (2010) 'The organization of extended producer responsibility in waste policy with product differentiation.' Journal of Environmental Economics and Management 59, 57-66

Frazer, Garth (2008) 'Used-clothing donations and apparel production in Africa.' The Economic Journal 118, 1764-1784

Janischweski, Jörg, Mikael P. Henzler, and W. Kahlenborn (2003) 'The export of secondhand goods and the transfer of technology.' Technical Report, The German Council for Sustainable Development

Rosenthal, Elisabeth (September 27, 2009) 'Smuggling Europe's waste to poorer countries.' The New York Times

Runkel, Marco (2003) 'Product durability and extended producer responsibility in solid waste management.' Environmental and Resource Economics 24, 161-182

Toffel, Michael W., Antoinette Stein, and Katharine L. Lee (2008) 'Extending producer responsibility: An evaluation framework for product take-back policies.' Technical Report, Harvard Business School

Yardley, Jim (April 23, 2010) 'Scrap metal rediation raises concerns in India.' The New York Times 